Afr. J. Trad. CAM (2006) 3 (2): 1 - 7

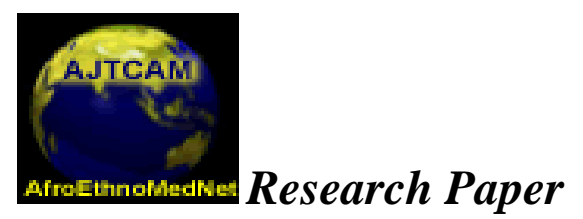

Afr. J. Traditional, Complementary and Alternative Medicines www.africanethnomedicines.net

ISSN 0189-6016@2006

\title{
CHEMICAL CONSTITUENTS AND ANTIMICROBIAL ACTIVITY OF A TRADITIONAL HERBAL MEDICINE CONTAINING GARLIC AND BLACK CUMIN
}

\author{
Jiben Roy $^{1}$ *, Diaa M. Shakleya ${ }^{2}$, Patrick S. Callery ${ }^{2}$ and John G. Thomas ${ }^{3}$ \\ Department of Chemistry, Division of Science \& Math, Mississippi University for \\ Women, Columbus, MS $39701^{2}$ Basic Pharmaceutical Sciences, West Virginia University, \\ Morgantown, WV 26506. ${ }^{3}$ Department of Pathology, School of Medicine, West Virginia \\ University, Morgantown, WV 26506.
}

*Email: jroy@muw.edu, Fax: 662-329-7238.

\begin{abstract}
A combination of crushed garlic (Allium sativum) and black cumin seeds (Nigelia sativum) has been used as a traditional remedy for urinary tract infections. In-vitro antimicrobial testing suggested that the mixture of two spices in the ratio of 1:1 has antimicrobial effects on both Staphylococcus aureus and Escherichia coli species. Analyses of the extract of garlic and black cumin by GC-MS as well as LC-MS \& MS $^{2}$ confirmed that the main components of garlic were allicin, $\gamma$-glutamyl-S-allylcysteine and allicin transformed products such as diallyldisulfide and vinyldithiins. Components of black cumin were thymoquinone, p-cymene, p-tert-butylcatechol, and pinene. Isolated samples of allicin by preparative HPLC from garlic extract and reference samples of diallyldisulfide and thymoquinone were tested individually and in combination for their antimicrobial activities against $S$. aureus and E. coli. All of these compounds showed modest antimicrobial effects individually (except diallyldisulfide against E. coli) and in combination.
\end{abstract}

Keywords: Garlic, Black cumin, Diallyldisulfide, Thymoquinone, Antimicrobial activity.

\section{Introduction}

Medicinal herbs and spices have long been used by mankind as traditional medicines for different diseases in many parts of the world. Because of the development of modern analytical tools, especially gas chromatography-mass spectrometry (GC-MS) and liquid chromatography-mass spectrometry (LC-MS), the constituents of medicinal herbs responsible for particular medicinal action have become easier to identify. Earlier studies (Roy et al., 1992) showed that a combination of fresh extracts of Allium sativum (garlic) 


\section{Afr. J. Trad. CAM (2006) 3 (2): 1 - 7}

and Nigella sativum (black cumin) in the proportion of 1:1 has more antibacterial sensitivity on the clinical isolates of urinary tract infections compared to individual extracts or of drugs such as cefalexin, cotrimoxazole, and nalidixic acid.

There are several reports (Johnston, 2002; Harris et al., 2001; Whittaker and Lawrence, 2000; Block, 1985) indicated that the sulfur containing volatile compound, allicin, is mainly responsible for the antibacterial effect of garlic. Recent reports (Avato et al.,2000; Tsao and Yin 2001; Tsao and Yin, 2001) suggested that other volatile compounds of garlic such as diallylmonosulfide, diallyldisulfide, and diallyltrisulfide were also found to have antimicrobial properties. Similarly, the pharmacologically active principles in the volatile oil of black cumin (Morsi, 2001; Ghosheh et al., 1999; Hanafy and Hatem, 1991) were identified as: thymoquinone, dithymoquinone, thymol and thymohydroquinone. The objective of this research was to identify components of the extracts of garlic and black cumin produced at room temperature and on heating and then examine the antibacterial effects using a 1:1 mixture of the extracts as well as the identified and isolated or purchased reference compounds.

\section{Materials and Methods}

Garlic was obtained locally from US markets and black cumin was purchased in Bangladesh. Distilled water and analytical grade diethyl ether, acetone, DMSO and methanol were used to extract spices or as control solvents for the antimicrobial testing.

\section{Gas Chromatography- Mass Spectrometry}

Agilent 6890 series GC system interfaced with Agilent 5973 mass selective detector. Column: DB-5MS-capillary column $(30 \mathrm{~m} \mathrm{X} 0.25 \mathrm{~mm}$ IDX0.2 micron film thickness). Oven temperature: The temperature profile employed was as follows: $50^{\circ} \mathrm{C}$ held for $1 \mathrm{~min}$ to $280{ }^{\circ} \mathrm{C}$ at $20{ }^{\circ} \mathrm{C} / \mathrm{min}$, transfer line at $280{ }^{\circ} \mathrm{C}$ with splitless injection. Mass spectrometer: Electron impact (EI) mode at $70 \mathrm{eV}$.

\section{High performance liquid chromatography}

BAS $200_{\mathrm{A}}$ liquid chromatograph; Column: Waters symmetry C-18 (5 micron); 3.9X150 mm, Mobile phase: Methanol: Water in $50: 50 \mathrm{v} / \mathrm{v}$ ratio under isocratic conditions; monitored at $254 \mathrm{~nm}$ by variable wavelength $\mathrm{UV}$ detector.

\section{Electrospray Mass Spectrometry and LC-MS Analysis}

The electrospray mass spectrometric analysis has been carried out using Finnigan LCQ ion trap mass spectrometer with direct injection of samples in $0.1 \%$ formic acid. LCMS was carried out through a BAS HPLC interfaced with the mass spectrometer at 20:1 split ratio. 
Afr. J. Trad. CAM (2006) 3 (2): 1 - 7

\section{Isolation, identification and quantification of allicin from fresh garlic extract}

Garlic $(5 \mathrm{~g})$ was crushed in $6 \mathrm{~mL}$ mixture of distilled water and methanol $(1: 1 \mathrm{v} / \mathrm{v})$, centrifuged at $2000 \mathrm{rpm}$ and filtered through $0.2 \mu \mathrm{m}$ filter-disc. The sample was then injected on HPLC interfaced with the mass spectrometer and allicin was identified from $\mathrm{MS}^{2}$ spectrum of $\mathrm{m} / \mathrm{z} 163$ ion. Allicin was then collected by preperative HPLC (Econosphere C-18, 10m, 250mm X 10mm, mobile phase: $\mathrm{H}_{2} \mathrm{O}: \mathrm{MeOH}$ with ratio 1:1, flow rate $3 \mathrm{~mL} / \mathrm{min}$, detection at $254 \mathrm{~nm}$ ). The concentration of allicin in the isolated fraction (Figure 1) was standardized spectrophotometrically using the following formula (Han, 1995):

\section{Identification of compounds using GC-MS}

$$
\mathrm{E}_{1 \mathrm{~cm}}{ }^{1 \%}=145.4 \text { at } 240 \mathrm{~nm}=\frac{(\text { Absorbance })}{\mathrm{C}(\mathrm{mg} / \mathrm{mL})}
$$

The identification of compounds from the extracts was made based on fragmentation patterns as well as matching of the mass spectra obtained from each sample with those in the NIST Mass Spectral Library.

\section{Direct vapor phase Analysis}

The blended crude sample (garlic or black cumin; $\sim 0.2 \mathrm{~g}$ ) taken in a small capped glass vial was heated for one minute $\left(\sim 100{ }^{\circ} \mathrm{C}\right)$ and then immediately sampled through the rubber septum using a $10 \mu 1$ syringe. The vapor sample was then injected manually onto the GC-MS.

\section{Antimicrobial activity}

Antimicrobial activity of the extracts and isolated allicin from garlic extract, black cumin and reference samples such as diallyldisulfide and thymoquinone were tested using the disk diffusion method. Two bacterial strains: gram +ve Staphylococcus aureus ATCC 6538 \& 29213 and gram -ve Escherchia coli ATCC 8739 \& 25922 were used. The Mueller-Hinton broth plate ( $150 \mathrm{~mL}$ size), sterile blank disc were purchased from Carolina Biologics, USA. The culture of the reference strains of bacteria were diluted according to McFarland scale 0.5 in a sterile solution of a normal saline at a concentration of $10^{5}$ $\mathrm{CFU} / \mathrm{mL}$. The plates of bacterial strains were incubated at $35^{\circ} \mathrm{C}$ and examined for zone inhibition after 18-20 hrs. For antimicrobial testing, garlic extract in water, ether extract of black cumin, allicin in water, diallyldisulphide and thymoquinone either in acetone solution or dimethylsulfoxide solution were used. Dimethylsulfoxide or acetone discs (dried on standing for $15 \mathrm{~min}$ ) were also used as negative controls. Nalidixic acid and cefipime discs were used as positive controls. A clear medium around the disc indicated inhibition of the microbial growth and the lowest concentration of the individual compound inhibiting the visible growth of each microorganism was determined as minimum inhibitory concentration (MIC) (Bylka, 2004). 
Afr. J. Trad. CAM (2006) 3 (2): 1 - 7

\section{Results and Discussion \\ GC-MS analysis of garlic vapor/extract}

Garlic is one of the plant materials that has been extensively studied for its composition and therapeutic uses. Allicin (diallyl thiosulfinate) is a major compound responsible for its antimicrobial activity. However, it is very thermo-labile and produces various disulfide compounds on heating (Han, 1995). Garlic vapor was formed on heating crushed garlic and the identified compounds were all disulfides. The ether extract, although prepared at room temperature, was exposed to high temperature in the GC injection port $\left(280{ }^{\circ} \mathrm{C}\right)$. This high temperature is conducive to thiosulfinate decomposition (Block, 1992). Another study (Itakura, 2001) confirmed that allicin in fresh garlic extracts was decomposed in the injection port of GC to produce vinyldithiins which were detected as major peaks of garlic extracts. We have also identified diallyldisulfide and vinyldithiin (Table 1).

\section{LC-MS Analysis of Garlic Extract}

HPLC separation of the components of aqueous extracts of garlic was examined on a C-18 column. In comparison to a reported retention time [11], the allicin peak has been tentatively identified. On heating the aqueous extract of garlic for about 10 minutes at boiling water, the allicin peak was reduced significantly as a result of thermal instability of allicin. In order to confirm the identity of the isolated allicin, the major antibacterial compound in garlic, the extracts were then analyzed by LC-MS and then had been isolated by preparative HPLC. The electrospray mass spectral fragmentation of allicin was found to be similar with published values (Calvey et al., 1994; Ferary et al.,1996). $\gamma$-Glutamyl-Sallylcysteine was also identified from its $(\mathrm{M}+\mathrm{H})^{+}$ion and the $\mathrm{MS}^{2}$ fragmentation pattern thereafter.

\section{GC-MS Analysis of Black Cumin Vapor/Extract}

The volatile oils of black cumin consist mostly of thymoquinone, dithymoquinone, thymohydroquinone, thymol as reported by Ghosheh et al.(1999). Our GC-MS analysis confirmed the presence of thymoquinone which is a major compound in the volatile oil, in addition to several other compounds (see Table 1).

\section{Antimicrobial Activity}

The concentrated water extract of garlic $(1 \mathrm{~g} / 2 \mathrm{~mL}$ water), the ether extract of black cumin and 1:1 combined extract showed antimicrobial responses to S. aureus and E. coli (inhibitory zone around $20-23 \mathrm{~mm}$ ). The heated water extract of garlic did not show an antimicrobial response. The combined 1:1 extract of garlic and black cumin, however, showed a larger inhibitory zone around the disc in comparison to individual extract of garlic and black cumin. From the identified components of both the extracts, allicin, diallyldisulfide from garlic and thymoquinone from black cumin were chosen for further 
Afr. J. Trad. CAM (2006) 3 (2): 1 - 7

Table 1: Electron Impact Mass Spectral Data of the identified compounds from Garlic and Black Cumin

\begin{tabular}{|c|c|}
\hline Name & Major Mass Spectral Data $\mathbf{m} / \mathbf{z}$ \\
\hline \multicolumn{2}{|c|}{ Identified compounds from Garlic extract } \\
\hline Methyl-2-propenyl disulfide & $41,120(\mathrm{M}), 45,39,79,73$ \\
\hline 1,3 Dithiin & $120(\mathrm{M}), 45,39,72$ \\
\hline Diallyldisulfide & $41,39,81,146(\mathrm{M}), 105,113$ \\
\hline Allylpropenyl disulfide & $41,39,45,61,73,105,146(\mathrm{M})$ \\
\hline 3-Vinyl-1,2-dithiocyclohexene & $111,144(\mathrm{M}), 103,97,85,77,71,45$ \\
\hline 3-Vinyl-1,2-dithiocyclohex-5-ene & $71,72,144(\mathrm{M}), 111,45,97$ \\
\hline \multicolumn{2}{|c|}{$\begin{array}{l}\text { Allicin and } \gamma \text {-Glutamyl-S-allylcysteine are identified from LC-electrospray mass } \\
\text { spectrometric analysis: }\end{array}$} \\
\hline Allicin: $(\mathrm{M}+\mathrm{H})^{+}$ion & $\mathrm{m} / \mathrm{z} 163$ and \\
\hline MS/MS of m/z163 & $163(2), 121(100), 87(15), 73(60)$ \\
\hline$\gamma$-Glutamyl-S-allylcysteine & $(\mathrm{M}+\mathrm{H})^{+}: \mathrm{m} / \mathrm{z} 291$ and \\
\hline MS/MS of 291 & $274(10), 273(9), 162(100), 145(45)$ \\
\hline \multicolumn{2}{|c|}{ Identified compounds from black cumin } \\
\hline$\alpha$-Phellandrene & $93,91,77,65,39,136(\mathrm{M})$ \\
\hline Pinene & $93,91,77,69,41,121,136(\mathrm{M})$ \\
\hline p-Cymeme & $119,134(\mathrm{M}), 91,77,65,51,39$ \\
\hline \multicolumn{2}{|c|}{ Thymoquinone } \\
\hline \multicolumn{2}{|c|}{$164(\mathrm{M}), 93,121,151,136,108,91,77,65,53,39$} \\
\hline \multicolumn{2}{|c|}{ 1,4-Methanozulene } \\
\hline \multicolumn{2}{|c|}{$161,91,105,119,133,147,79,175,189,204(\mathrm{M})$} \\
\hline p-tert.Butylcatechol & $151,166(\mathrm{M}), 133,123,105,95,77,65,55$ \\
\hline Citronellol & $41,69,95,81,109,121,129,156(\mathrm{M})$ \\
\hline n-Hexadecanoic acid & $43,39,73,55,129,213,239,256(\mathrm{M})$ \\
\hline
\end{tabular}

antimicrobial activity. The blank disc impregnated with allicin solution in water at a concentration of $0.21 \mathrm{mg} / \mathrm{mL}$ (MIC) was found to be active against E. coli, Staph. aureus and the combination of both organisms. Similar results were obtained using thymoquinone at a concentration of $1.7 \mathrm{mg} / \mathrm{mL}$ (MIC). However, diallyldisulfide did show activity against Staph. aureus $(3.5 \mathrm{mg} / \mathrm{mL}$, MIC) only and not against E. coli. Fresh garlic extract, on the other hand, also showed antimicrobial activity against $E$. coli. perhaps because of the presence of allicin in the extract, which is active against both E.coli and Staph. aureus. The results suggest that the antimicrobial activity of a mixture of garlic and black cumin against E. coli \& Staph. aureus can be explained by additive effects of allicin and diallyldisulphide from garlic extracts and thymoquinone from black cumin. 
Afr. J. Trad. CAM (2006) 3 (2): 1 - 7

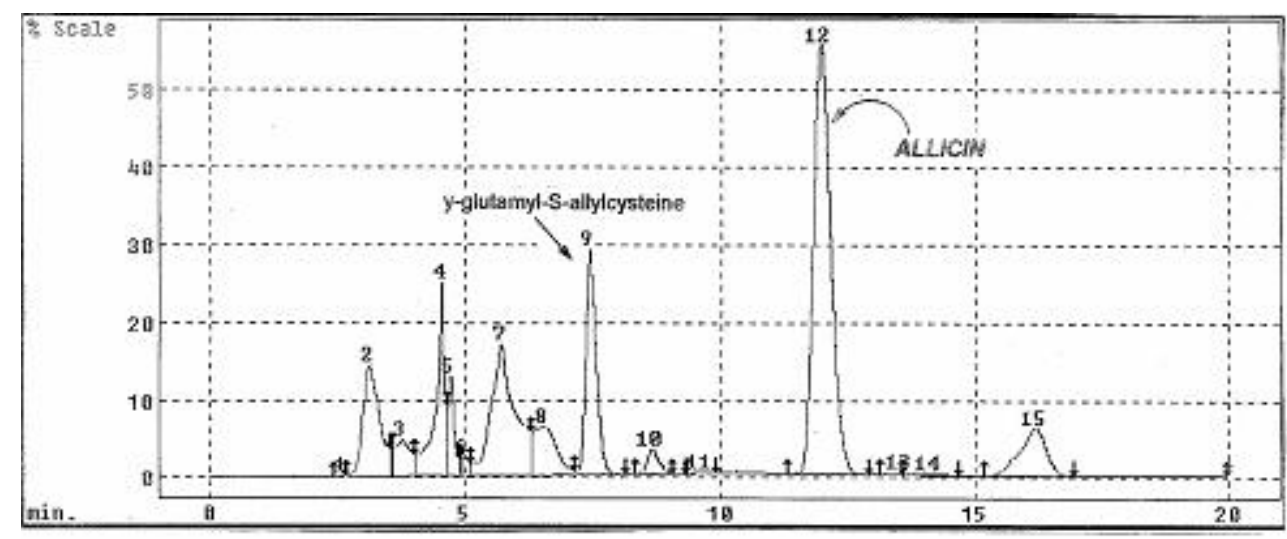

Figure 1: Preparative high performance liquid chromatogram of methanolic aqueous extract of garlic: Column - Econosphere C -18, $10 \mu, 250 \mathrm{~mm} \mathrm{X} 10 \mathrm{~mm}$; Flow rate- $3 \mathrm{~mL} / \mathrm{min}$, mobile phase $-\mathrm{H}_{2} \mathrm{O}: \mathrm{MeOH}=50: 50$, detection- $\mathrm{UV} 254 \mathrm{~nm}$

\section{Conclusion}

This investigation has been undertaken to look at chemical constituents of both the herbal ingredients- garlic and black cumin seeds, identify the major bioactive compounds and study their antimicrobial activities against the causative pathogens of urinary tract infection. This study has confirmed the fact that allicin of freshly crushed garlic and thymoquinone of black cumin seeds are the major components, which have great therapeutic potential as antimicrobial agents against different pathogens including Staphylococcus aureus and E. coli species. However, the combination of the two ingredients has additive effects rather than synergistic antimicrobial effects.

\section{Acknowledgements}

This research was supported in part by grant RR16477 from the National Center for Research Resources awarded to the West Virginia Biomedical Research Infrastructure Network (under which Faculty summer fellowship awarded to Jiben Roy while he was a faculty at Salem International University, WV).

The authors are thankful to Madhu Sanga and Steven Wolfe of West Virginia University and Dilip K. Sarker of Quality Control Laboratory, Square Pharmaceutical Ltd of Bangladesh for their help with the initial GC, HPLC and microbiological work.

\section{References}

1. Avato, P., Tursil, E.., Vitali, C., Miccolis, V. and Candido V. (2000). Allylsulfide constituents of garlic volatile oil as antimicrobial agents, Phytomedicine 7(3):239-43. 
Afr. J. Trad. CAM (2006) 3 (2): 1 - 7

2. Block, E., Naganathan S., Putman D., and Zhao S.H. (1992). Allium Chemistry: HPLC analysis of thiosulfinates from Onion, Garlic, Wild Garlic, Leek, Scalliont, Elepant Garlic, Chive and Chinese Chive. Uniquely high allyl to methyl ratios in some garlic samples, J Agric Food Chem 40:2418-2430.

3. Block, E. (1985). The chemistry of garlic and onion, Scientific American 252: 114119.

4. Bylka, W., Szaufer-Hajrych, M., Matawska, I. and Goslinska, O. (2004). Antimicrobial activity of isocytisoside and extracts of Aquilegia vulgaris L., Letters Appl Microbiol 39(1): 93-97.

5. Calvey, E. M., Roach, J. A. G. and Block, E. (1994). A Supercritical fluid chromatography of garlic (Allium sativum) extracts with mass spectrometric identification of allicin., J. Chrom. Sci. 32(3): 93-96.

6. Ferary, S., Thibout, E. and Auger, J. (1996). Direct analysis of odors emitted by freshly cut allium using combined high-performance liquid chromatography and mass spectrometry, Rapid Comm Mass Spectrom. 10: 1327-1332.

7. Ghosheh, O. A., Houdi, A. A. and Crooks, P. A. (1999). High performance liquid chromatographic analysis of the pharmacogically active quinine and related compounds in the oil of the black seed (Nigella sativa L.), J Pharm. Biomed. Anal. 19(5): 757-762.

8. Han, J., Lawson, L., Hand, G. and Han, P. (1995). A spectrophotometric method for quantitative determination of allicin and total garlic thiosulfinates, Anal Biochem 225: 157-160.

9. Hanafy, M. S. and Hatem, M.E. (1991). Studies on the antimicrobial activity of Nigella sativa seed (black cumin), J Ethnopharmacol 34(2-3): 275-278.

10. Harris, J. C., Cottrell, S.L., Plummer, S. and Lloyd, D. (2001). Antimicrobial properties of Allium Sativum (garlic), Appl Microbiol Biotechnol 57(3): 282-286.

11. Itakura, Y., Ichikawa, M., Mori, Y., Okino, R., Vdayama, M. and Morita T. (2001).

12. Johnston, N. (2002). Garlic: A natural antibiotic, MDD 5(4):12-12.

13. Morsi, N. M. (2000). Antimicrobial effect of crude extracts of Nigella sativa on multiple antibiotics- resistant bacteria, Acta Microbiol Pol 49(1): 63-74.

14. Tsao, S. M. and Yin, M. C. (2001). In vitro activity of garlic oil and four diallyl sulfides against antibiotic-resistant Pseudomonas aeruginosa and Klebsiella pneumoniae, J. Antimicrob Chemother 47(5): 665-670.

15. Tsao, S.M. and Yin, M.C. (2001). In vitro antimicrobial activity of four diallyl sulfides occurring in Garlic and chinese leek oils, J Med Microbiol 50(7): 646-649.

16. Roy, J., Khan, I. H., Dutta, A. K., Sarker M.H., Choudhuri, S. K. and Mahmud, M. (1992). Traditional therapy using a mixture of allium sativum (garlic) and nigella sativum in the treatment of urinary tract infections, Bangladesh renal J. 11(1):13-17.

17. Whittaker, T. and Lawrence, S. (2000). The use of garlic in the treatment of bacterial infections in Antibiotic Today, Supplement of Chimica Oggi- Chemistry Today; Teknoscienze Pub. Itali. p39. 